\title{
Morfologia oral interna de larvas dos gêneros Eupemphix, Physalaemus e Leptodactylus (Amphibia: Anura)
}

\author{
Núbia Esther de Oliveira Miranda ${ }^{1,3}$ \& Adelina Ferreira ${ }^{2}$ \\ ${ }^{1}$ Laboratório de Anatomia Comparativa de Vertebrados, \\ Departamento de Ciências Fisiológicas (CFS), Instituto de Biociências, Universidade de Brasília - UnB, \\ ICC-Sul, Módulo 5, Campus Darcy Ribeiro, CEP 70910-900, Brasília, DF, Brasil \\ ${ }^{2}$ Departamento de Biologia e Zoologia, Instituto de Biociências, \\ Universidade Federal de Mato Grosso - UFMT, \\ Av. Fernando Correa da Costa, s/n, Coxipó, CEP 78060-900, Cuiabá, MT, Brasil \\ ${ }^{3}$ Autor para correspondência: Núbia Esther de Oliveira Miranda, e-mail:estherbio@ gmail.com
}

MIRANDA, N.E.O. \& FERREIRA, A. 2009. Internal buccal morphology of the tadpoles of the genera Eupemphix, Physalaemus and Leptodactylus (Amphibia: Anura). Biota Neorop., 9(2): http://www.biotaneotropica. org.br/v9n2/en/abstract?article+bn02909022009.

\begin{abstract}
The internal buccal morphology of the tadpoles of Eupemphix nattereri, Physalaemus albonotatus, P. centralis, P. cuvieri, Leptodactylus furnarius, L. fuscus, L. petersii and L. podicipinus are described and compared using scanning electron microscopy. The tadpole of $E$. nattereri has major differences when compared to other tadpoles of the Physalaemus genus. The tadpoles of $P$. albonotatus, $P$. centralis and $P$. cuvieri present similarities in internal buccal morphology, such as the number of the infralabial and lateral ridge papillae, but $P$. centralis differ in the number of the post-narial and buccal roof arena papillae. Among the tadpoles of the Leptodactylus species is possible to observe patterns, in distribution and quantity of the internal buccal structures (infralabial and lingual papillae, buccal floor and roof arena papillae, median ridge, lateral ridge papillae and postnarial papillae) in the species groups. The characteristics of the internal buccal morphology may be useful when used together with other data helping in comprehension of the systematic of the order Anura.

Keywords: internal buccal anatomy, description, tadpole, Leiuperidae, Leptodactylidae.
\end{abstract}

MIRANDA, N.E.O. \& FERREIRA, A. 2009. Morfologia bucal interna de larvas dos gêneros Eupemphix, Physalaemus e Leptodactylus (Amphibia: Anura) Biota Neorop., 9(2): http://www.biotaneotropica.org.br/v9n2/ pt/abstract?article+bn02909022009.

Resumo: A morfologia bucal interna das larvas de Eupemphix nattereri, Physalaemus albonotatus, P. centralis, P. cuvieri, Leptodactylus furnarius, L. fuscus, L. petersii e L. podicipinus são descritas e comparadas utilizando microscopia eletrônica de varredura. A larva de E. nattereri apresenta muitas diferenças quando comparada à larvas de anuros do gênero Physalaemus. As larvas de $P$. albonotatus, $P$. centralis e $P$. cuvieri apresentam semelhanças em sua morfologia bucal interna, tais como o número de papilas infralabiais e papilas laterais à crista mediana. P. centralis difere na quantidade de papilas pós-nasais e papilas da arena do teto bucal. Entre as larvas de Leptodactylus é possível perceber um padrão na distribuição e quantidade das estruturas bucais internas (papilas infralabiais e linguais, papilas das arenas do assoalho e teto bucal, crista mediana, papilas laterais da crista e papilas pós-nasais) nos grupos de espécies. Os caracteres da morfologia bucal larvária podem ser úteis quando utilizados conjuntamente com outros dados auxiliando na compreensão das relações sistemáticas da ordem Anura.

Palavras-chave: anatomia bucal interna, descrição, girinos, Leiuperidae, Leptodactylidae. 


\section{Introdução}

As larvas dos anfíbios anuros apresentam uma grande diversidade de hábitos alimentares e de distribuição microespacial com adaptações na morfologia bucal externa e interna, as quais constituem um conjunto de informações úteis na compreensão das relações ecológicas e sistemáticas da ordem Anura (Wassersug 1976, D’Heursel \& de Sá 1999, Eterovick \& Sazima 2000, Haas 2003, Pugener et al. 2003, Weber \& Carasmachi 2006). Especificamente quanto à morfologia bucal interna, a presença ou ausência, número e arranjo das estruturas de seleção e captura de partículas, tais como: papilas linguais, papilas da arena das arenas do teto e do assoalho bucal e crista mediana, podem estar intimamente correlacionadas à distribuição espacial, partilha do uso de recursos, dieta e comportamento de forrageamento (Sokol 1975, Wassersug 1976, Wassersug \& Duellman 1984). O entendimento dessas relações auxilia na resolução de problemas taxonômicos (Sokol 1975, Wassersug 1976, Wassersug \& Duellmann 1984, Haas 2003, D'Heursel \& Haddad 2007).

Recentemente, foi proposta uma nova sistemática para a classe Lissamphibia combinando análises moleculares e morfológicas de adultos e larvas (Frost et al. 2006, Grant et al. 2006). Com essas mudanças, a família Leptodactylidae foi reformulada e atualmente contém 96 espécies, distribuídas nos gêneros Hydrolaetare Gallardo, 1963, Leptodactylus Fitzinger, 1826, Paratelmatobius Lutz e Carvalho, 1958 e Scythrophrys Lynch, 1971 (Frost 2008, Caramaschi et al. 2008). Os gêneros Edalorhina Jiménez de La Espada, 1870, Engystomops Jiménez de La Espada, 1872, Eupemphix Steindachner, 1863, Physalaemus Fitzinger, 1826, Pleurodema Tschudi, 1838, Pseudopaludicola Miranda-Ribeiro, 1926 e Somuncuria Lynch, 1978 foram retirados da família Leptodactylidae, passando a constituir a família Leiuperidae (Grant et al. 2006). Essas mudanças são importantes, uma vez que servem de base para novos estudos sistemáticos e filogenéticos do grupo em estudo. Neste sentido, este trabalho tem por objetivo descrever a anatomia bucal interna de espécies de anuros pertencentes às famílias Leiuperidae e Leptodactylidae, buscando fornecer novos caracteres que possam auxiliar na compreensão das relações taxonômicas da ordem Anura.

\section{Material e Métodos}

Foram analisadas larvas de Eupemphix nattereri Steindachner, 1863, Physalaemus albonotatus (Steindachner, 1864), P. centralis Bokermann, 1962 e P. cuvieri Fitzinger, 1826, pertencentes à família Leiuperidae e, de Leptodactylus furnarius Sazima e Bokermann, 1978, L. fuscus (Schneider, 1799), L. petersii (Steindachner, 1864) e L. podicipinus (Cope, 1862), pertencentes à família Leptodactylidae, coletadas em regiões pertencentes à porção norte do Pantanal Matogrossense e aos municípios de Cuiabá e Chapada dos Guimarães, no estado de Mato Grosso. Todos os espécimes analisados foram depositados na Coleção Zoológica de Vertebrados da Universidade Federal de Mato Grosso. Os estágios de desenvolvimento foram determinados segundo Gosner (1960). Medidas (em milímetros) do comprimento do corpo (CC) e comprimento total (CT) foram obtidas com o auxílio de um paquímetro Mitutoyo ${ }^{\circledR}$ com precisão de $0,01 \mathrm{~mm}$ sob lupa. Para cada larva estudada, o assoalho e teto bucal foram dissecados e caracterizados segundo metodologia e terminologia propostas por Wassersug (1976). As amostras foram desidratadas em concentrações crescentes de álcool, secas ao ponto crítico, cobertas com ouro paládio em aparelho do tipo sputtering, analisadas e fotodocumentadas em Microscopia Eletrônica de Varredura (Jeol JSM 5800LV).

\section{Material analisado}

- Eupemphix nattereri: (UFMT 5506), Chapada dos Guimarães MT, $14^{\circ} 54^{\prime}$ S e $55^{\circ} 42^{\prime} \mathrm{W}$. Duas larvas analisadas: estágio 36, $\mathrm{CC}=9,68 \mathrm{~mm}, \mathrm{CT}=25,40 \mathrm{~mm}$; estágio $36, \mathrm{CC}=9,48 \mathrm{~mm}$, $\mathrm{CT}=25,90 \mathrm{~mm}$.

- Physalaemus albonotatus: (UFMT 5549), Cuiabá - MT, $15^{\circ} 36^{\prime} 28.83^{\prime \prime}$ S e $56^{\circ} 3^{\prime} 43.97$ ' W. Duas larvas analisadas: estágio $36, \mathrm{CC}=9,41 \mathrm{~mm}, \mathrm{CT}=24,84 \mathrm{~mm}$; estágio 37 , $\mathrm{CC}=9,76 \mathrm{~mm}, \mathrm{CT}=26,12 \mathrm{~mm}$.

- P. centralis: (UFMT 5546), Nossa Senhora do Livramento MT, 573815 L e 8191057 N. Duas larvas analisadas: estágio 36, $\mathrm{CC}=5,46 \mathrm{~mm}, \mathrm{CT}=16,07 \mathrm{~mm}$; estágio $38, \mathrm{CC}=7,36 \mathrm{~mm}$, $\mathrm{CT}=20,95 \mathrm{~mm}$.

- P. cuvieri: (UFMT 5505), Chapada dos Guimarães - MT, $14^{\circ} 54^{\prime} \mathrm{S}$ e $55^{\circ} 42^{\prime} \mathrm{W}$. Duas larvas analisadas: estágio 38 , $\mathrm{CC}=8,19 \mathrm{~mm}, \mathrm{CT}=23,99 \mathrm{~mm}$; estágio $39, \mathrm{CC}=8,86 \mathrm{~mm}$, $\mathrm{CT}=20,00 \mathrm{~mm}$.

- Leptodactylus furnarius: (UFMT 5502), Chapada dos Guimarães - MT, $14^{\circ} 54^{\prime}$ S e $55^{\circ} 42^{\prime}$ W. Duas larvas analisadas: estágio $35, \mathrm{CC}=9,0 \mathrm{~mm}, \mathrm{CT}=23,34 \mathrm{~mm}$; estágio 37 , $\mathrm{CC}=11,12 \mathrm{~mm}, \mathrm{CT}=31,33 \mathrm{~mm}$.

- L. fuscus: (UFMT 5503), Chapada dos Guimarães - MT, $14^{\circ} 54^{\prime} \mathrm{S}$ e $55^{\circ} 42^{\prime} \mathrm{W}$. Duas larvas analisadas: estágio 37 , $\mathrm{CC}=10,71 \mathrm{~mm}, \mathrm{CT}=27,26 \mathrm{~mm}$; estágio $38, \mathrm{CC}=10,43 \mathrm{~mm}$, $\mathrm{CT}=27,72 \mathrm{~mm}$.

- L. petersii: (UFMT 5550), Várzea Grande-MT, $15^{\circ} 37^{\prime} 45.85^{\prime}$ S e $56^{\circ} 5$ ' 39.80" W. Duas larvas analisadas: estágio 36, $\mathrm{CC}=7,70 \mathrm{~mm}, \mathrm{CT}=21,32 \mathrm{~mm}$; estágio $37, \mathrm{CC}=8,03 \mathrm{~mm}$, $\mathrm{CT}=22,38 \mathrm{~mm}$.

- L. podicipinus: (UFMT 5504), Corumbá-MS, $17^{\circ}$ 50' 58.51”S e $57^{\circ} 32$ ' 08.71" W. Duas larvas analisadas: estágio 38, $\mathrm{CC}=10,60 \mathrm{~mm}, \mathrm{CT}=28,65 \mathrm{~mm}$; estágio $38, \mathrm{CC}=10,29 \mathrm{~mm}$, $\mathrm{CT}=30,91 \mathrm{~mm}$.

\section{Resultados}

\section{Eupemphix nattereri Steindachner, 1863}

- Assoalho bucal: É de formato triangular (Figura 1a). Cinco papilas infralabiais estão presentes: a papila central é menor e triangular e as dos pares laterais internos e externos são altas e cilíndricas; as papilas do par lateral interno apresentam seus ápices recobertos por pústulas (Figura 1b). O rudimento lingual tem formato de elipse e apresenta quatro papilas linguais, as duas centrais são mais altas que as laterais, todas em formato cilíndrico (Figura 1b). A arena do assoalho bucal é delimitada por cerca de 10 papilas de cada lado, as quais são cônicas e altas (Figura 1c). As bolsas bucais são profundas e estreitas. O velum ventral é extenso e apresenta quatro pequenas projeções de cada lado da glote. A zona glandular ventral restringe-se à superfície dorsal do bordo velar (Figura 1c).

- Teto bucal: É de formato triangular e ligeiramente mais estreito que o assoalho. Três papilas estão presentes de cada lado do teto bucal (Figura 1d). A arena pré-nasal tem formato de trapézio. Em sua porção posterior, à frente das coanas destaca-se uma crista em formato de arco retangular recoberta por pústulas (Figura 1d). As coanas são ovais e estão orientadas obliquamente ao plano transverso. A parede anterior da narina é mais baixa que a parede posterior e é coberta por pequenas pústulas (Figura 1d). Quatro papilas pós-nasais estão presentes, duas de cada lado; o par anterior é constituído de papilas altas, cônicas, com a margem anterior recobertas por pústulas; o par posterior é constituído por papilas baixas, cônicas e lisas; todas as papilas 
apresentam seus ápices dirigidos para a crista mediana. A arena pós-nasal é triangular, curta e estreita, sendo delimitada posteriormente por uma crista mediana semicircular recoberta por pústulas; algumas pústulas estão presentes na arena pós-nasal. Quatro papilas laterais da crista estão presentes, localizadas duas de cada lado da crista mediana, apresentam suas bases fundidas, são altas, cônicas e com seus ápices voltados para a crista; a borda anterior das papilas laterais da crista está recoberta de pústulas (Figura 1d). A arena do teto bucal tem formato retangular e é delimitada por cinco papilas de cada lado; as três anteriores são menores que as duas posteriores, todas são cônicas e com ápices voltados para o centro da arena. Cerca de 50 pústulas encontram-se dispersas no centro da arena. A zona glandular está restrita a uma faixa na porção posterior do velum dorsal (Figura 1d).

\section{Physalaemus albonotatus (Steindachner, 1864)}

- Assoalho bucal: É de formato triangular (Figura 2a). Quatro papilas infralabiais estão presentes, as papilas do par central apresentam suas bases fundidas. Todas são cilíndricas e sem pústulas. O rudimento lingual tem formato de elipse e apresenta quatro papilas linguais, todas de mesmo tamanho e de formato cilíndrico, dispostas em uma fileira transversal (Figura 2a,b). A arena do assoalho bucal é triangular e delimitada por cinco papilas de cada lado, as quais são cônicas, altas e com ápices voltados para o centro da arena. Cerca de três papilas menores agrupam-se lateralmente nos limites anteriores do velum ventral. As bolsas bucais estão dispostas transversalmente e não são perfuradas. Cinco a sete papilas estão localizadas na região anterior às bolsas bucais. $\mathrm{O}$ velum ventral apresenta projeções na borda e a zona glandular é pouco perceptível, restringindo-se à superfície dorsal do bordo velar.

- Teto bucal: É de formato triangular e ligeiramente mais estreito que o assoalho bucal (Figura 2c). Apresenta uma arena pré-nasal de formato oval, na qual está presente uma crista em formato de $\mathrm{V}$ recoberta por pústulas. As coanas são ovais e estão orientadas transversalmente. Duas papilas pós-nasais estão presentes. A arena pós-nasal é triangular, curta e estreita,
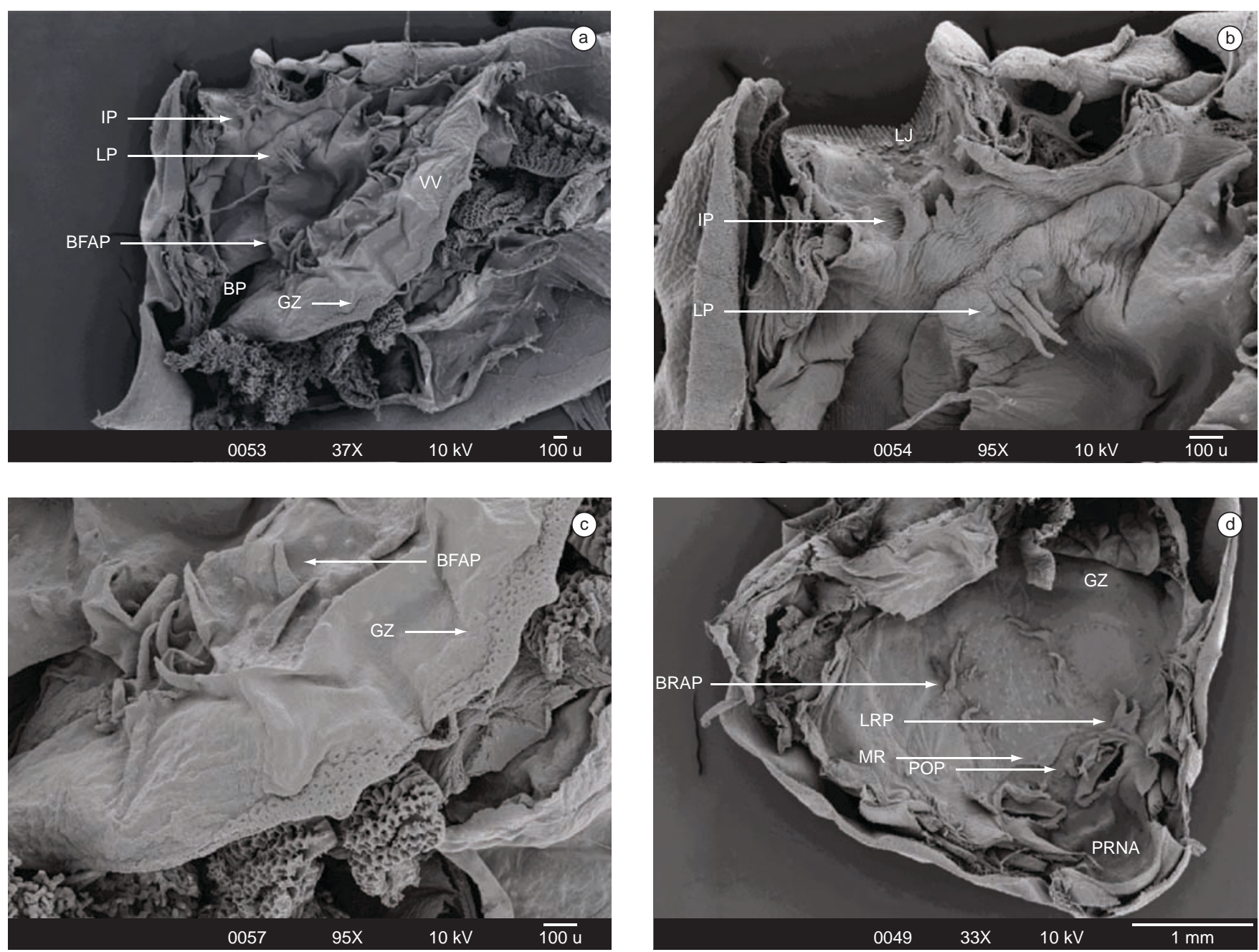

Figura 1. Imagens obtidas em microscopia eletrônica de varredura (MEV) do assoalho (a-c) e teto (d) bucal da larva de Eupemphix nattereri (estágio 36). $\mathrm{BFAP}=$ papilas da arena do assoalho bucal $\mathrm{BP}=$ bolsa bucal $; \mathrm{BRAP}=$ papilas da arena do teto bucal; $\mathrm{GZ}=\mathrm{zona}$ glandular; $\mathrm{IP}=$ papilas infralabiais; $\mathrm{LJ}=\mathrm{cobertura}$ da mandíbula inferior; $\mathrm{LP}=$ papilas linguais; $\mathrm{LRP}=$ papila lateral à crista mediana; $\mathrm{MR}=$ crista mediana; $\mathrm{POP}=$ papilas pós-nasais; $\mathrm{PRNA}=$ arena pré-nasal; $\mathrm{VV}=$ velum ventral.

Figure 1. Scanning electron microscopy (SEM) of the floor (a-c) and roof (d) of oral cavity of Eupemphix nattereri tadpole (stage 36). BFAP = buccal floor arena papillae; $\mathrm{BP}=$ buccal pocket; $\mathrm{BRAP}=$ buccal roof arena papillae; $\mathrm{GZ}=$ glandular zone; $\mathrm{IP}=$ infralabial papillae; $\mathrm{LJ}=$ lower jaw; LP = lingual papillae; $\mathrm{LRP}=$ lateral ridge papillae; $\mathrm{MR}=$ median ridge; $\mathrm{POP}=$ postnarial papillae; $\mathrm{PRNA}=$ prenarial papillae; $\mathrm{VV}=\mathrm{velum}$ ventral. 

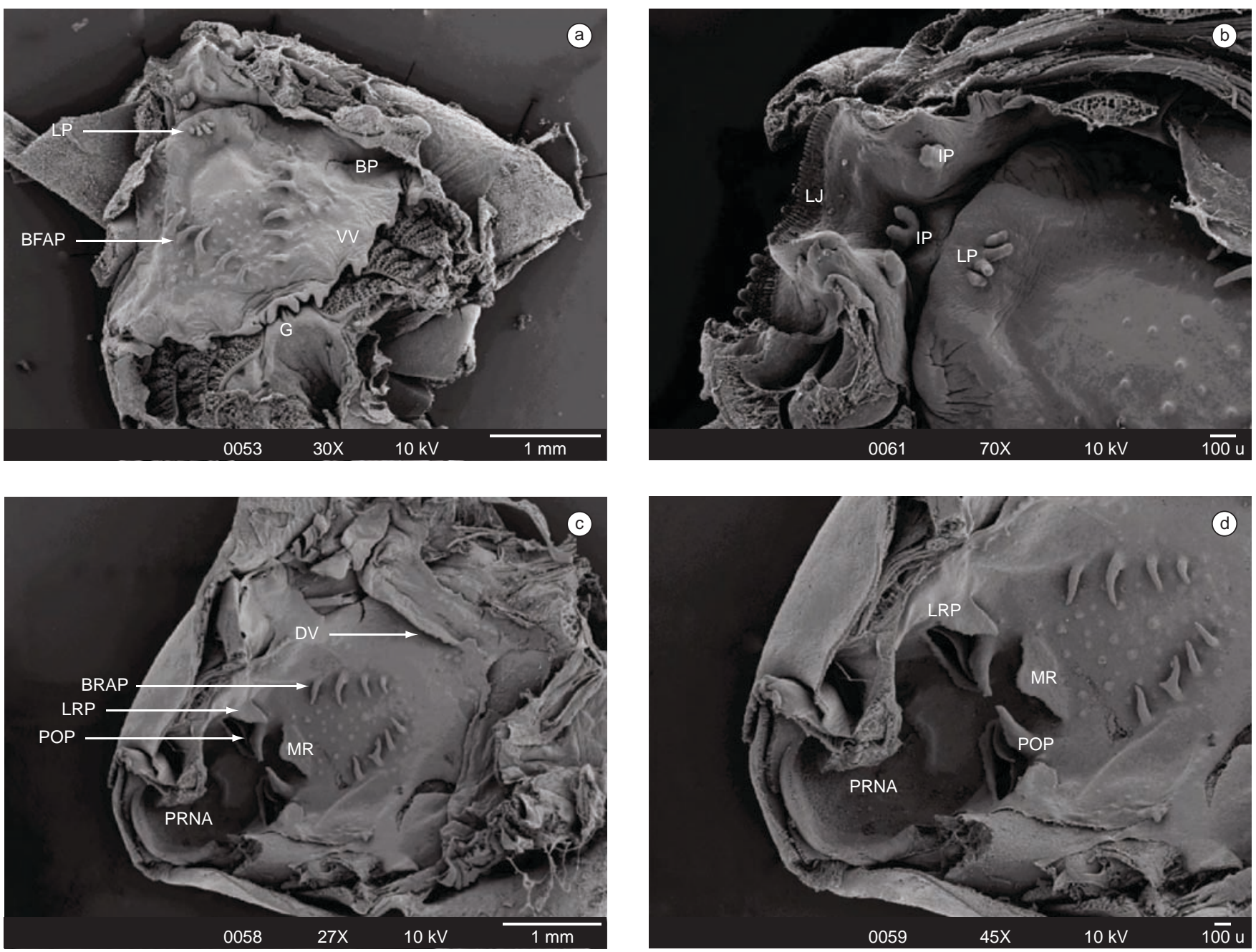

Figura 2. Imagens obtidas MEV do assoalho (a-b) e teto (c-d) bucal da larva de Physalaemus albonotatus (estágio 36). BFAP = papilas da arena do assoalho bucal; $\mathrm{BP}=$ bolsa bucal; $\mathrm{BRAP}=$ papilas da arena do teto bucal; $\mathrm{DV}=$ velum dorsal; $\mathrm{G}=$ glote; $\mathrm{IP}=$ papilas infralabiais; $\mathrm{LJ}=$ cobertura da mandíbula inferior; $\mathrm{LP}=$ papilas linguais; $\mathrm{LRP}=$ papila lateral à crista mediana; $\mathrm{MR}=$ crista mediana; $\mathrm{POP}=$ papilas pós-nasais; $\mathrm{PRNA}=$ arena pré-nasal; $\mathrm{VV}=$ velum ventral.

Figure 2. Scanning electron microscopy (SEM) of the floor (a-b) and roof (c-d) of oral cavity of Physalaemus albonotatus tadpole (stage 36). BFAP = buccal floor arena papillae; $\mathrm{BP}=$ buccal pocket; $\mathrm{BRAP}=$ buccal roof arena papillae; $\mathrm{DV}=$ dorsal velum; $\mathrm{G}=$ glottis; $\mathrm{IP}=$ infralabial papillae; $\mathrm{LJ}=$ lower jaw; $\mathrm{LP}=$ lingual papillae; $\mathrm{LRP}=$ lateral ridge papillae; $\mathrm{MR}=$ median ridge; $\mathrm{POP}=$ postnarial papillae; $\mathrm{PRNA}=$ prenarial papillae; $\mathrm{VV}=$ velum ventral.

sendo delimitada posteriormente por uma crista mediana triangular de margem irregular. Um par de papilas laterais da crista, simples e triangulares, está presente (Figura 2d). A arena do teto bucal tem formato de trapézio e é delimitada por quatro papilas de cada lado, as duas anteriores são maiores que as duas posteriores. Aproximadamente 40 pústulas encontram-se dispersas no centro da arena. A zona glandular está restrita a uma faixa na porção posterior do velum dorsal, o qual apresenta pequenas projeções.

\section{Physalaemus centralis Bokermann, 1962}

- Assoalho bucal: É de formato triangular (Figura 3a). Quatro papilas infralabiais estão presentes, as papilas do par central são menores que as papilas externas e todas são recobertas por pústulas (Figura 3b). O rudimento lingual tem formato de elipse e apresenta três papilas linguais. As papilas são altas, cônicas, ramificadas com a papila central localizada um pouco mais a frente que as papilas laterais (Figura 3b). A arena do assoalho bucal é quadrangular e é delimitada por seis a oito papilas de cada lado. As bolsas bucais estão dispostas transversalmente e não são perfuradas. Três papilas estão localizadas na região anterior às bolsas bucais. O velum ventral não apresenta projeções. A zona glandular é pouco perceptível, restringindo-se à superfície dorsal do bordo velar.

- Teto bucal: É de formato triangular e ligeiramente mais estreito que o assoalho bucal (Figura 3c). Apresenta uma arena pré-nasal em formato de trapézio, na qual algumas pústulas estão presentes (Figura 3d). As coanas são ovais e estão dispostas ligeiramente oblíquas ao plano transverso. Seis papilas pós-nasais estão presentes (Figura 3d). A arena pós-nasal tem formato de trapézio e é delimitada posteriormente por uma crista mediana semicircular de margem irregular. Três pústulas estão presentes na arena pós-nasal. Um par de papilas laterais da crista está presente, as papilas são ramificadas (Figura 3d). A arena do teto bucal é quadrangular e delimitada por três a quatro papilas de cada lado, todas de tamanho variado e dispostas irregularmente. Aproximadamente 15 pústulas encontram-se dispersas no centro da arena. A zona glandular está distribuída 

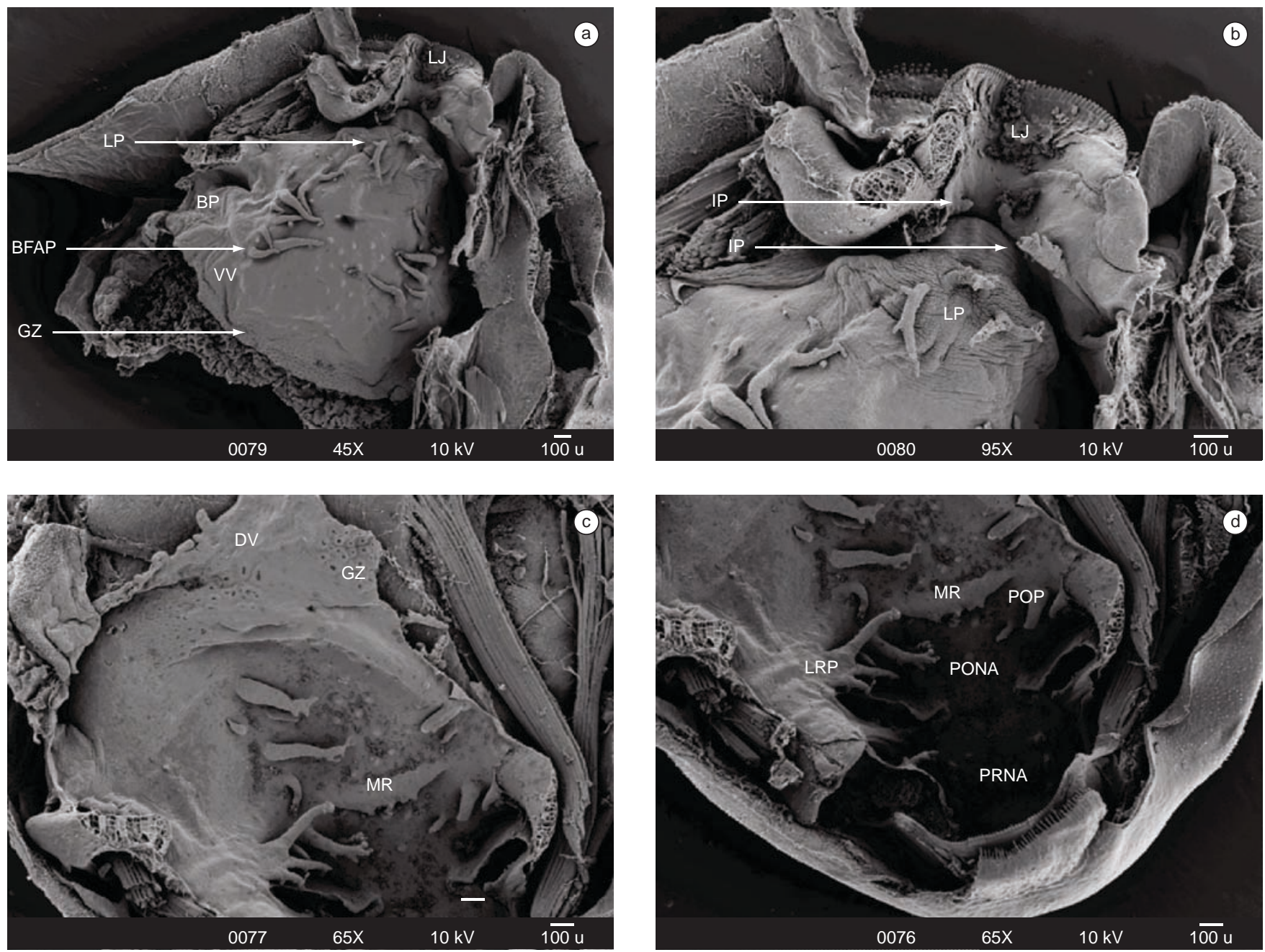

Figura 3. Imagens obtidas MEV do assoalho (a-b) e teto (c-c) bucal da larva de Physalaemus centralis (estágio 38). BFAP= papilas da arena do assoalho bucal; $\mathrm{BP}=$ bolsa bucal; $\mathrm{DV}=$ velum dorsal; $\mathrm{GZ}=$ zona glandular; $\mathrm{IP}=$ papilas infralabiais; $\mathrm{LJ}=$ cobertura da mandíbula inferior; $\mathrm{LP}=$ papilas linguais; $\mathrm{LRP}=$ papila lateral à crista mediana; $\mathrm{MR}=$ crista mediana; $\mathrm{PONA}=$ arena pós-nasal; $\mathrm{POP}=$ papilas pós-nasais; $\mathrm{PRNA}=$ arena pré-nasal; $\mathrm{VV}=$ velum ventral.

Figure 3. Scanning electron microscopy (SEM) of the floor (a-b) and roof (c-d) of oral cavity of Physalaemus centralis tadpole (stage 38). BFAP = buccal floor arena papillae; $\mathrm{BP}=$ buccal pocket; $\mathrm{DV}=$ dorsal velum; $\mathrm{GZ}=$ glandular zone; $\mathrm{IP}=$ infralabial papillae; $\mathrm{LJ}=$ lower jaw; $\mathrm{LP}=$ lingual papillae; $\mathrm{LRP}=$ lateral ridge papillae; $\mathrm{MR}=$ median ridge; $\mathrm{PONA}=$ postnarial arena; $\mathrm{POP}=$ postnarial papillae; $\mathrm{PRNA}=$ prenarial papillae; $\mathrm{VV}=$ velum ventral.

em pequenas manchas e o velum dorsal apresenta pequenas projeções.

\section{Physalaemus cuvieri Fitzinger, 1826}

- Assoalho bucal: É de formato triangular (Figura 4a). Quatro papilas infralabiais estão presentes, as papilas do par externo são altas e triangulares e as papilas do par central são muito reduzidas e cônicas. Todas as papilas são recobertas por pústulas (Figura 4b). O rudimento lingual é oval e apresenta três papilas linguais, as quais são pequenas e cilíndricas e estão dispostas medialmente no rudimento lingual (Figura 4b). A arena do assoalho bucal é arredondada e delimitada por três papilas de cada lado. As papilas anteriores apresentam suas bases fundidas. As bolsas bucais estão dispostas transversalmente e não são perfuradas (Figura 4c). Oito papilas estão localizadas na região anterior às bolsas bucais (Figura 4c). O velum ventral não apresenta projeções e a zona glandular é pouco perceptível.
- Teto bucal: É de formato triangular e ligeiramente mais estreito que o assoalho bucal (Figura 4d). Apresenta uma arena pré-nasal em formato oval, a qual apresenta algumas pústulas. As coanas são ovais e estão dispostas ligeiramente oblíquas ao plano transverso. Duas papilas pós-nasais estão presentes. Apresenta uma arena pós-nasal triangular, delimitada posteriormente por uma crista mediana semicircular com margem pustulada; duas pústulas estão presentes na arena pós-nasal. Um par de papilas laterais da crista está presente, as papilas são triangulares, com a margem anterior pustulada e com as bases fundidas (Figura 4d). A arena do teto bucal é retangular, delimitada por duas papilas de cada lado, com cerca de 30 pústulas dispersas. A zona glandular ocupa cerca de $1 / 3$ do velum dorsal, o qual apresenta pequenas projeções (Figura 4d).

\section{Leptodactylus furnarius Sazima \& Bokermann, 1978}

- Assoalho bucal: É de formato triangular (Figura 5a). Dois pares de papilas infralabiais estão presentes, sendo que as papilas do par anterior, localizado na linha mediana, apresentam as bases 

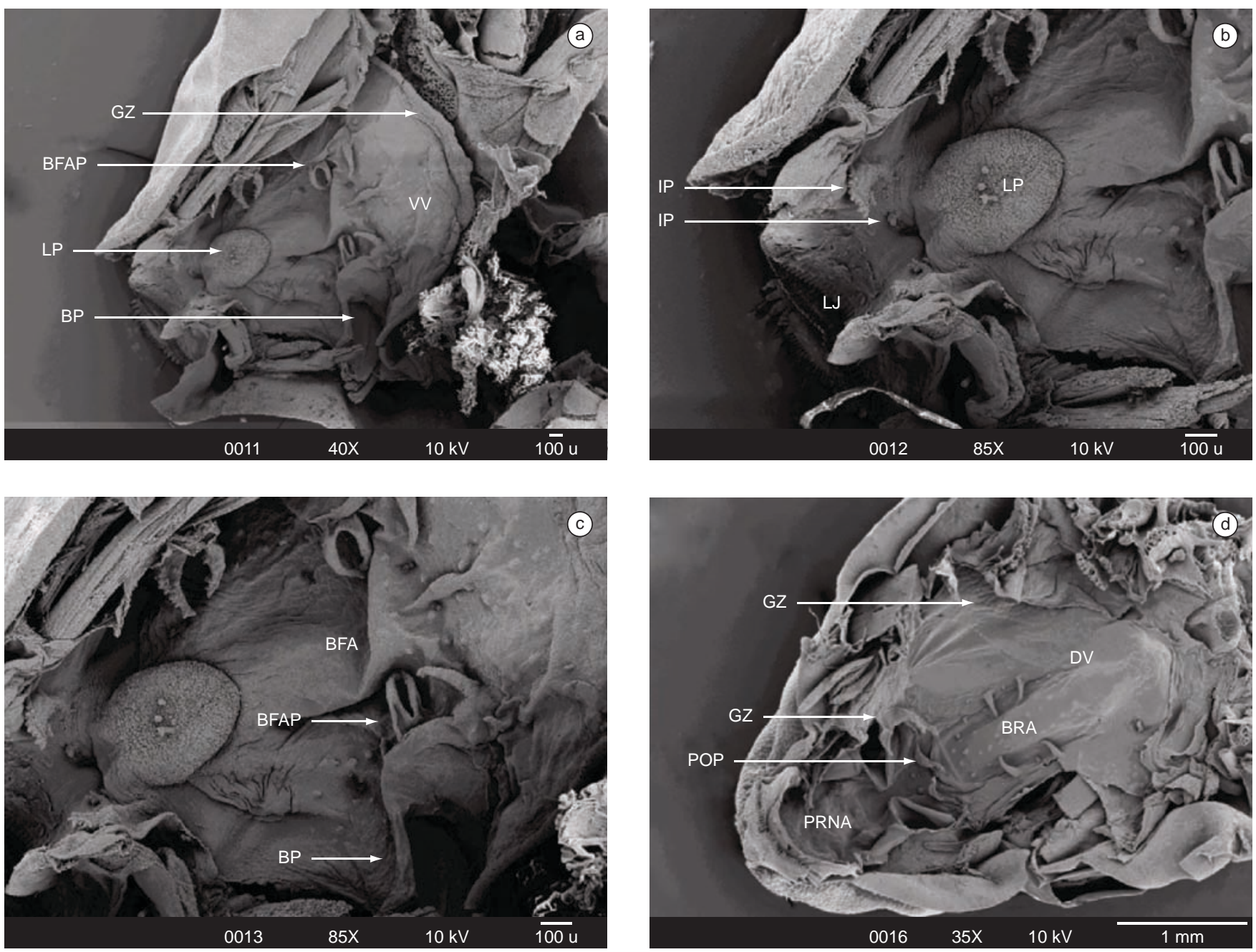

Figura 4. Imagens obtidas MEV do assoalho (a-c) e teto (d) bucal da larva de Physalaemus cuvieri (estágio 39). BFA = arena do assoalho bucal; $\mathrm{BFAP}=$ papilas da arena do assoalho bucal; $\mathrm{BP}=$ bolsa bucal; $\mathrm{DV}=$ velum dorsal; $\mathrm{GZ}=$ zona glandular; $\mathrm{IP}=$ papilas infralabiais; $\mathrm{LJ}=$ cobertura da mandíbula inferior; $\mathrm{LP}=$ papilas linguais; $\mathrm{LRP}=$ papila lateral à crista mediana; $\mathrm{POP}=$ papilas pós-nasais; $\mathrm{PRNA}=$ arena pré-nasal; $\mathrm{VV}=$ velum ventral.

Figure 4. Scanning electron microscopy (SEM) of the floor (a-c) and roof (d) of oral cavity of Physalaemus cuvieri tadpole (stage 39). BFA = buccal floor arena; $\mathrm{BFAP}=$ buccal floor arena papillae; $\mathrm{BP}=$ buccal pocket; $\mathrm{DV}=$ dorsal velum; $\mathrm{GZ}=$ glandular zone; $\mathrm{IP}=$ infralabial papillae; $\mathrm{LJ}=$ lower jaw; $\mathrm{LP}=$ lingual papillae; LRP = lateral ridge papillae; $\mathrm{POP}=$ postnarial papillae; $\mathrm{PRNA}=$ prenarial papillae; $\mathrm{VV}=$ velum ventral.

fundidas. Estão presentes quatro papilas linguais dispostas em fileira transversal, são todas de mesmo tamanho e em formato cilíndrico (Figura 5a). A arena do assoalho bucal tem formato retangular, e é delimitada por nove a 10 papilas cônicas e altas de cada lado, e possui cerca de 50 pústulas distribuídas na arena. As bolsas bucais são estreitas e não apresentam perfurações. Quatro papilas estão presentes na região anterior às bolsas bucais. O velum ventral é extenso, apresenta quatro projeções de cada lado da glote, e possui uma zona glandular restrita à superfície dorsal das suas projeções. A glote encontra-se descoberta (Figura 5a).

- Teto bucal: Semelhante ao formato do assoalho, no entanto um pouco mais estreito (Figura 5b). A arena pré-nasal é ampla e uma crista em formato de M, recoberta por pústulas, está presente em sua porção posterior logo à frente das coanas (Figura 5b). As coanas são elípticas, sendo que a parede anterior da narina é mais alta que a parede posterior e está coberta por pequenas pústulas. Duas papilas pós-nasais, altas, cônicas e com a margem recoberta por pústulas estão presentes. A arena pós-nasal é triangular e estreita, sendo delimitada por uma crista mediana semicircular. Apresenta um par de papilas laterais da crista, as quais são cônicas e recobertas por pústulas (Figura 5b). A arena do teto bucal tem formato retangular e é delimitada por quatro papilas altas e cônicas de cada lado, com os ápices voltados para o centro da arena; aproximadamente 90 pústulas encontram-se dispersas no centro da arena. O velum dorsal é estreito e apresenta uma zona glandular restrita a uma faixa em sua porção posterior (figura $5 b$ ).

\section{Leptodactylus fuscus (Schneider, 1799)}

- Assoalho bucal: É de formato triangular (Figura 5c). Apresentam dois pares de papilas infralabiais, sendo que as papilas do par anterior, localizado na linha mediana, apresentam suas bases fundidas. Estão presentes quatro papilas linguais, dispostas em fileira transversal (Figura 5c). A arena do assoalho bucal tem formato triangular e é delimitada por oito a nove papilas cônicas de cada lado; cerca de 40 pústulas encontram-se espalhadas na arena do assoalho bucal (Figura 5c). As bolsas bucais são estreitas e não apresentam perfurações. Seis a sete 

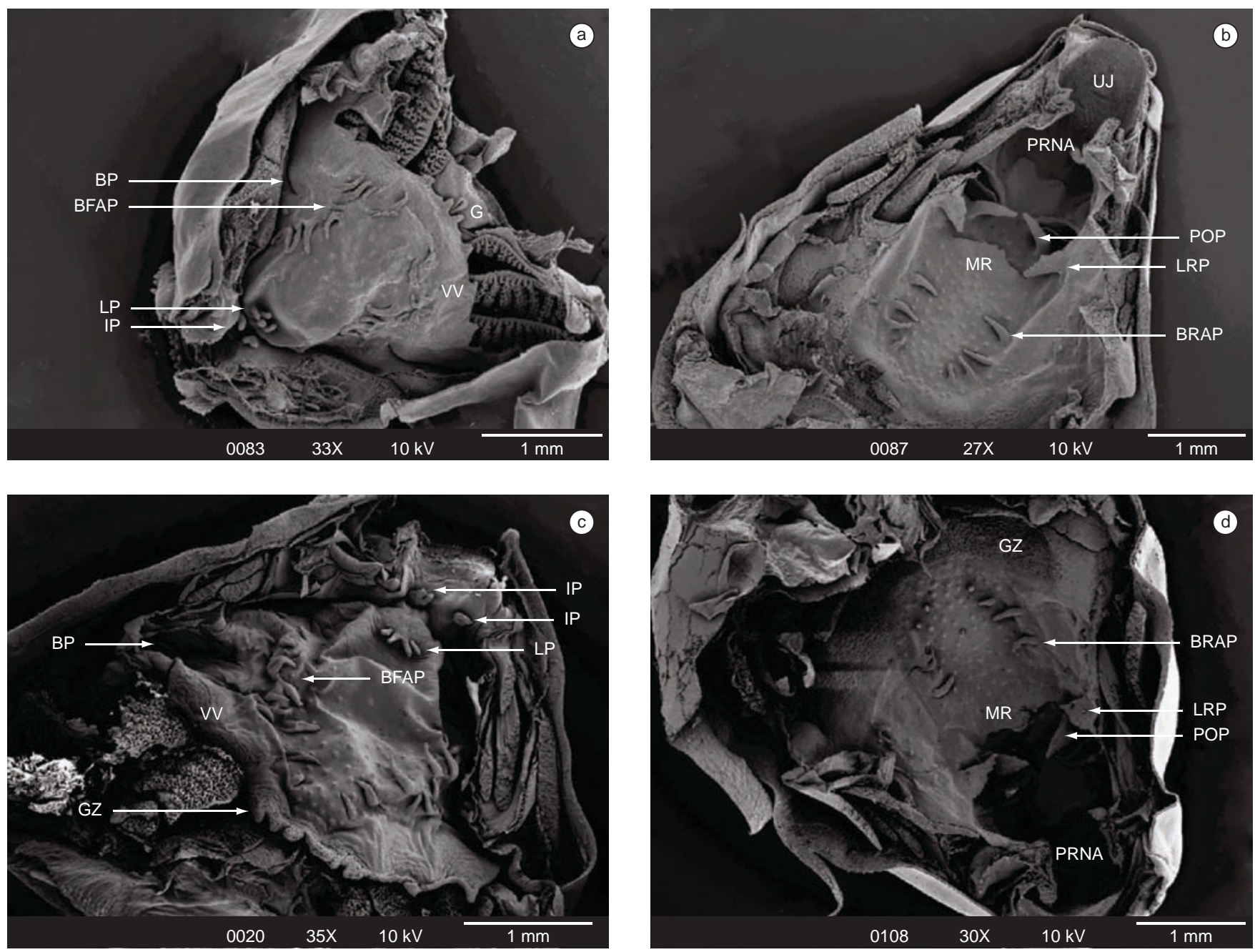

Figura 5. Imagens obtidas em MEV do assoalho (a) e teto bucal (b) da larva de Leptodactylus furnarius (estágio 37), e do assoalho (c) e teto bucal (d) da larva de $L$. fuscus (estágio 37). $\mathrm{BFAP}=$ papilas da arena do assoalho bucal; $\mathrm{BP}=$ bolsa bucal; $\mathrm{BRAP}=$ papilas da arena do teto bucal; $\mathrm{G}=\mathrm{glote} ; \mathrm{GZ}=\mathrm{zona}$ glandular; IP = papilas infralabiais; $\mathrm{LP}=$ papilas linguais; $\mathrm{LRP}=$ papilas laterais da crista; $\mathrm{MR}=$ crista mediana; $\mathrm{POP}=$ papila pós-nasal; $\mathrm{PRNA}=$ arena prénasal; $\mathrm{UJ}=$ cobertura da mandíbula superior; $\mathrm{VV}$ = velum ventral.

Figure 5. Scanning electron microscopy (SEM) of the floor (a) and roof (b) of oral cavity of Leptodactylus furnarius tadpole (stage 37), and of the floor (c) and roof (d) of oral cavity of $L$. fuscus tadpole ( stage 37). BFAP = buccal floor arena papillae; $\mathrm{BP}=$ buccal pocket; $\mathrm{BRAP}=$ buccal roof arena papillae; $\mathrm{G}=$ glottis; $\mathrm{GZ}=$ glandular zone; $\mathrm{IP}=$ infralabial papillae; $\mathrm{LP}=$ lingual papillae; $\mathrm{LRP}=$ lateral ridge papillae; $\mathrm{MR}=$ median ridge; $\mathrm{POP}=$ postnarial papillae; $\mathrm{PRNA}=$ prenarial arena; $\mathrm{UJ}=$ upper jaw; $\mathrm{VV}=$ velum ventral.

papilas estão presentes na região anterior às bolsas bucais. O velum ventral é extenso e apresenta quatro projeções de cada lado da glote. A zona glandular está restrita à superfície dorsal das projeções velares. A glote encontra-se descoberta (Figura 5c).

- Teto bucal: Semelhante ao formato do assoalho, no entanto um pouco mais estreito (Figura 5d). A arena pré-nasal é ampla e uma crista larga em formato de M está presente em sua porção posterior logo à frente das coanas (Figura $5 \mathrm{~d}$ ). As coanas são elípticas e estão orientadas transversalmente. Apresenta um par de papilas pós-nasais, altas, cônicas e com a margem anterior recoberta por pústulas. A arena pós-nasal é triangular e estreita, sendo delimitada por uma crista mediana semicircular. Possui um par de papilas laterais da crista, as quais são altas, triangulares e recobertas por pústulas (Figura 5d). A arena do teto bucal tem formato retangular e é delimitada por quatro papilas altas e cônicas de cada lado, com os ápices voltados para o centro da arena; aproximadamente 50 pústulas estão distribuídas no centro da arena. A zona glandular é ampla e estende-se por todo o velum dorsal, o qual é amplo (Figura 5d).

\section{Leptodactylus petersii (Steindachner, 1864)}

- Assoalho bucal: É de formato triangular. Três papilas infralabiais estão presentes, todas cônicas, altas e recobertas por pústulas. Não apresenta papilas linguais. A arena do assoalho bucal é trapezoidal, delimitada por 11 a12 papilas de cada lado, as quais são cônicas, de tamanho variável, e com ápices voltados para o centro da arena; cerca de seis papilas agrupam-se lateralmente nos limites anteriores do velum ventral. Aproximadamente 25 pústulas estão distribuídas na arena. As bolsas bucais são largas e profundas e não apresentam perfurações. Cinco a seis papilas estão presentes na região anterior às bolsas bucais. O velum ventral é extenso, apresenta quatro projeções de cada lado da glote, e possui uma zona glandular restrita à superfície dorsal de suas projeções. A glote encontra-se descoberta (Figura 6a). 

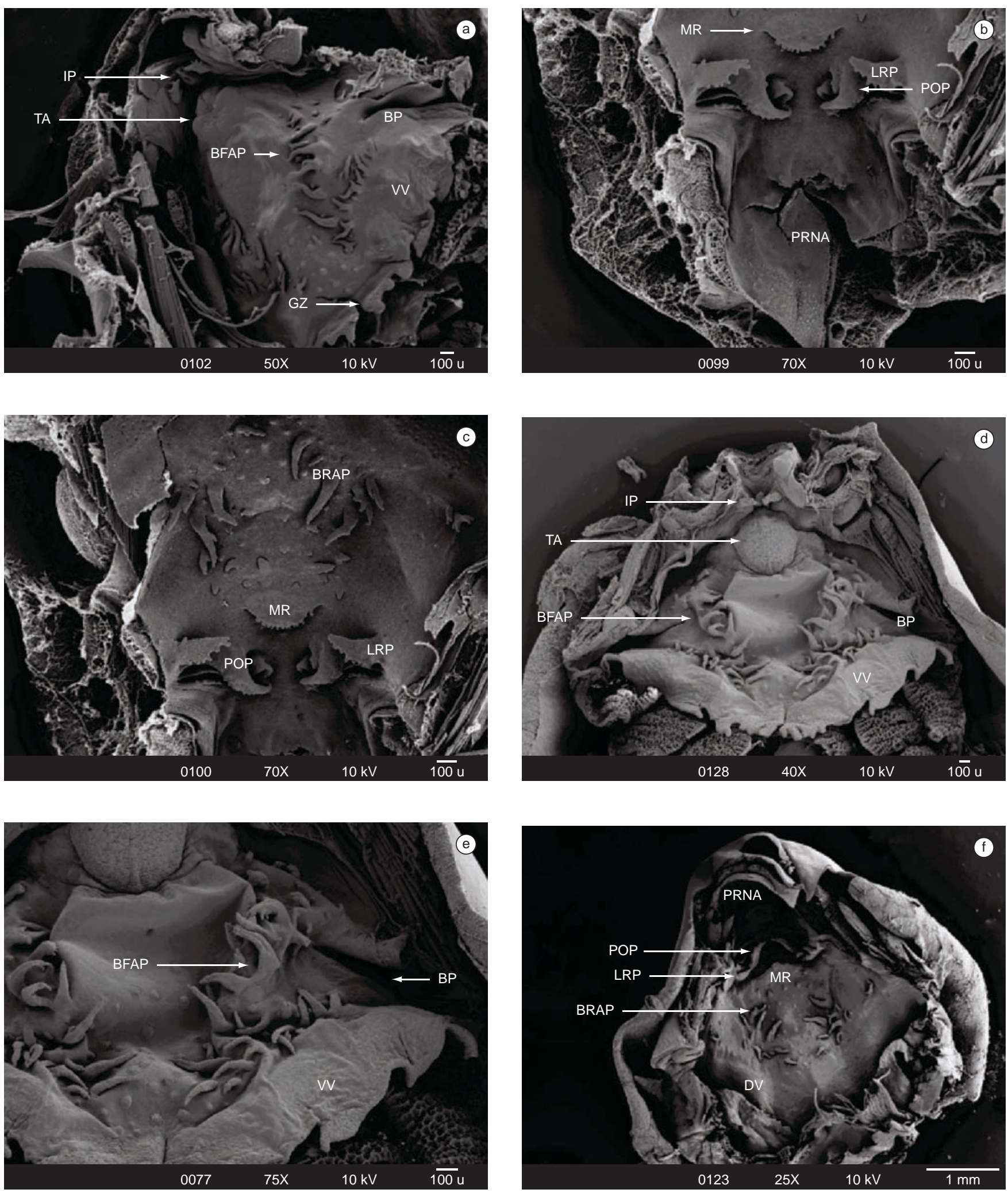

Figura 6. Imagens obtidas em MEV do assoalho (a) e teto bucal (b-c) da larva de Leptodactylus petersii (estágio 36), e do assoalho (d-e) e teto bucal (f) da larva de $L$. podicipinus (estágio 38). $\mathrm{BFAP}=$ papilas da arena do assoalho bucal; $\mathrm{BP}=$ bolsa bucal; $\mathrm{BRAP}=$ papilas da arena do teto bucal; $\mathrm{DV}=\mathrm{velum}$ dorsal; GZ = zona glandular; IP = papilas infralabiais; LRP = papilas laterais da crista; $\mathrm{MR}=$ crista mediana; $\mathrm{POP}=$ papila pós-nasal; $\mathrm{PRNA}=$ arena pré-nasal; $\mathrm{TA}=$ rudimento lingual $; \mathrm{VV}=$ velum ventral.

Figure 6. Scanning electron microscopy (SEM) of the floor (a) and roof (b-c) of oral cavity of Leptodactylus petersii tadpole (stage 36), and of the floor (d-e) and roof (f) of oral cavity of $L$. podicipinus tadpole ( stage 38 ). BFAP = buccal floor arena papillae; $\mathrm{BP}=$ buccal pocket; $\mathrm{BRAP}=$ buccal roof arena papillae; $\mathrm{DV}$ = dorsal velum; $\mathrm{GZ}=$ glandular zone; $\mathrm{IP}=$ infralabial papillae; $\mathrm{LRP}=$ lateral ridge papillae; $\mathrm{MR}=$ median ridge; $\mathrm{POP}=$ postnarial papillae; $\mathrm{PRNA}=$ prenarial arena; $\mathrm{TA}=$ tongue anlage; $\mathrm{VV}=$ velum ventral. 
- Teto bucal: Semelhante ao formato do assoalho, no entanto um pouco mais estreito. A arena pré-nasal é ampla e uma crista em formato de $\mathrm{M}$, recoberta por pústulas, está presente em sua porção posterior logo à frente das coanas (Figura 6b). As coanas são elípticas e estão orientadas transversalmente. A parede anterior da narina, coberta por pequenas pústulas, é mais baixa que a parede posterior. Possui um par de papilas pós-nasais, altas, cônicas e com a margem anterior recoberta por pústulas (Figura 6b). A arena pós-nasal triangular e estreita é delimitada por uma crista mediana semicircular. Está presente um par de papilas laterais da crista, as quais são altas, triangulares e recobertas por pústulas (Figura 6b). A arena do teto bucal é triangular, delimitada por cinco a seis papilas cônicas de cada lado, dispostas irregularmente e com ápices voltados para o centro da arena; aproximadamente 35 pústulas encontram-se dispersas por toda a arena. A zona glandular é ampla e estende-se por todo o velum dorsal, o qual é amplo (Figura 6c).

\section{Leptodactylus podicipinus (Cope, 1862)}

- Assoalho bucal: É de formato triangular (Figura 6d). Três papilas infralabiais estão presentes, todas cônicas, altas e recobertas por pústula. Não apresenta papilas linguais (Figura 6d). A arena do assoalho bucal tem formato de trapézio e é delimitada por seis a sete papilas de formato cônico de cada lado, com tamanho variável e com ápices voltados para o centro da arena; aproximadamente 15 papilas agrupam-se lateralmente nos limites anteriores do velum ventral e 15 pústulas estão distribuídas na arena (Figura 6e). As bolsas bucais são largas e profundas e não apresentam perfurações. Três a quatro papilas estão presentes na região anterior às bolsas bucais. $\mathrm{O}$ velum ventral é extenso, apresenta quatro projeções de cada lado da glote. A zona glandular restringe-se à superfície dorsal das projeções do velum. A glote encontra-se descoberta.

- Teto bucal: Semelhante ao formato do assoalho, no entanto um pouco mais estreito (Figura 6f). A arena pré-nasal é ampla e uma crista em formato de M, recoberta por pústulas, está presente em sua porção posterior logo à frente das coanas (Figura 6f). As coanas são elípticas. A parede anterior da narina é mais alta que a parede posterior e está coberta por pequenas pústulas. Possui um par de papilas pós-nasais, altas, cônicas e com a margem anterior recoberta por pústulas. A arena pós-nasal triangular e estreita é delimitada por uma crista mediana triangular. Apresenta um par de papilas laterais da crista, as quais são altas, cônicas e recobertas por pústulas (Figura 6f). A arena do teto bucal tem formato trapezoidal, é delimitada por sete a oito papilas cônicas de cada lado, de tamanho variável, e com ápices voltados para o centro da arena; aproximadamente 20 pústulas encontram-se dispersas no centro da arena (Figura 6f). A zona glandular é ampla e estende-se por todo o velum dorsal, o qual é amplo e apresenta pequenas projeções.

\section{Discussão}

Lynch (1970), com base em análises de esqueleto e morfologia externa, propôs que a separação entre os gêneros Eupemphix e Physalaemus (classicamente separados com base na presença ou ausência de dentes maxilares) era inconsistente e invalidou o gênero Eupemphix. O autor transferiu a única espécie de Eupemphix (E. nattereri) para o gênero Physalaemus, no grupo de espécies de $P$. biligonigerus, alegando que os caracteres diagnósticos dos gêneros eram inconsistentes para mantê-los separados. Contudo Nascimento et al. (2005), com base em análises de morfometria, morfologia externa, padrões de coloração e osteologia, propuseram a revalidação de Eupemphix.

Assim como o adulto, a larva de Eupemphix nattereri também apresenta algumas diferenças em relação a larvas de anuros do gênero Physalaemus (Tabela 1), particularmente quando comparadas as de $P$. biligonigerus, $P$. marmoratus e $P$. santafecinus, espécies que também pertenciam ao grupo de $P$. biligonigerus (Lynch 1970) e que atualmente estão alocadas no grupo de $P$. albifrons (Nascimento et al. 2005, Nascimento et al. 2006). No assoalho bucal, Eupemphix nattereri apresenta quatro papilas linguais, enquanto que P. biligonigerus, $P$. marmoratus e $P$. santafecinus apresentam uma ou duas papilas (Perotti \& Cespedez 1999, Sandoval \& Alvarez 2001, Nomura et al. 2003). Eupemphix nattereri também apresenta uma maior quantidade de papilas limitando a arena do assoalho bucal. No teto bucal $E$. nattereri apresenta um par a mais de papilas laterais à crista mediana do que as outras três espécies.

Physalaemus albonotatus, $P$. centralis e $P$. cuvieri pertencem ao grupo de $P$. cuvieri, ao qual também pertencem $P$. cicada, $P$ cuqui, $P$. ephippifer, $P$. erikae, $P$. fischeri e $P$. kroyeri (Nascimento et al. 2005). As informações sobre a morfologia larvária das espécies pertencentes a este grupo são escassas. Somente quatro espécies (Physalaemus albonotatus, . centralis, $P$. cuqui e $P$. cuvieri) possuem as larvas descritas (Bokermann 1962, Cei 1980, Heyer et al. 1990, Rossa-Feres \& Jim 1993, Perotti 1997, Kehr et al. 2004, Rossa-Feres \& Nomura 2006).

Physalaemus albonotatus, $P$. centralis e $P$. cuvieri apresentam em comum a presença de quatro papilas infralabiais no assoalho da cavidade bucal, sendo que o par central apresenta a base fundida nas larvas de $P$. albonotatus e é menor em relação ao par externo nas larvas de $P$. centralis e $P$. cuvieri, e a presença de três a quatro papilas linguais. Esta última característica difere da apresentada pelas larvas pertencentes aos grupos de espécies de albifrons e henselii, as larvas destes grupos apresentam no máximo duas papilas linguais e mesmo a presença da segunda papilas parece estar relacionada a variações intra-específicas (Perotti \& Cespedez 1999, Sandoval \& Alvarez 2001, Alcade et al. 2006). O aspecto geral do teto bucal mostrou-se menos conservativo entre as espécies do grupo, porém evidencia maior semelhança entre as espécies $P$. albonotatus e $P$. cuvieri e diferenças entre estas e $P$. centralis (Tabela 1).

O gênero Leptodactylus Fitzinger, 1826 é um gênero Neotropical que ocorre da América do Norte (sul do Texas) até a América do Sul (Frost 2008). Heyer (1969) definiu cinco grupos de espécies para o gênero: L. ocellatus, L. melanonotus, L. pentadactylus, L. fuscus e L. marmoratus. Sete espécies (Leptodactylus elenae, L. fuscus, L. gracilis, L. latinasus, L. mystacinus, L. notoaktites e L. spixi) pertencentes ao grupo de L. fuscus possuem a morfologia oral interna de suas larvas descritas (Wassersug \& Heyer 1988, Sandoval 2004, Bilate et al. 2006, Prado \& D’Heursel 2006, de Sá et al. 2007b). Entre os caracteres comuns do assoalho da cavidade bucal podemos citar: o número de papilas linguais (quatro), sendo que nas larvas de L. notoaktites três papilas linguais estão presentes (de Sá et al. 2007b); glote descoberta e a presença de dois pares de papilas infralabiais com o par medial fundido (Sandoval 2004, Prado \& D'Heursel 2006, este trabalho). Esta última característica não é compartilhada pelas larvas de L. fuscus, provenientes do município de Teresópolis no estado do Rio de Janeiro, Brasil (Wassersug \& Heyer 1988), que apresentam três papilas infralabiais em fileira transversal, nem pelas larvas de L. notoaktites (de Sá et al. 2007b) e L. spixi (Bilate et al. 2006), que apresentam os dois pares com o par central não fundido (Tabela 2). $\mathrm{O}$ aspecto geral do teto bucal mostrou-se mais conservativo entre as espécies do grupo (Tabela 3), com duas a quatro papilas pós-nasais, formato semicircular da crista mediana, um par de papilas laterais 
Miranda, N.E.O. \& Ferreira, A.

Tabela 1. Comparação da morfologia bucal interna das larvas de Eupemphix nattereri e Physalaemus.

Table 1. Comparison of internal buccal morphology of the tadpoles of Eupemphix nattereri and Physalaemus.

\begin{tabular}{|c|c|c|c|c|c|c|c|c|c|}
\hline $\begin{array}{c}\text { Grupo de espécies/ } \\
\text { espécie }\end{array}$ & $\begin{array}{c}\text { Papilas } \\
\text { infralabiais }\end{array}$ & $\begin{array}{c}\text { Papilas } \\
\text { linguais }\end{array}$ & $\begin{array}{c}\text { Papilas } \\
\text { AAB } \\
\text { (por lado) }\end{array}$ & $\begin{array}{c}\text { Papilas } \\
\text { BB } \\
\text { (por lado) }\end{array}$ & $\begin{array}{c}\text { Projeções } \\
\text { velum } \\
\text { ventral } \\
\end{array}$ & $\begin{array}{c}\text { Papilas } \\
\text { pós-nasais }\end{array}$ & $\begin{array}{l}\text { Formato } \\
\text { da crista } \\
\text { mediana }\end{array}$ & $\begin{array}{c}\text { Papilas } \\
\text { LC } \\
\text { (por lado) } \\
\end{array}$ & $\begin{array}{c}\text { Papilas } \\
\text { ATB } \\
\text { (por lado) } \\
\end{array}$ \\
\hline E. nattereri ${ }^{\mathrm{A}}$ & 5 & 4 & 10 & ---- & presentes & 4 & $\begin{array}{l}\text { semicircular, coberta } \\
\text { por pústulas }\end{array}$ & 2 & 5 \\
\hline \multicolumn{10}{|l|}{ P. albifrons } \\
\hline P. biligonigerus ${ }^{\mathrm{B}}$ & 4 & $1-2$ & 5 & ---- & ausentes & 2 & $\begin{array}{l}\text { semicircular com } \\
\text { margem irregular }\end{array}$ & 1 & $5-8$ \\
\hline P. marmoratus $\mathrm{C}^{\mathrm{C}}$ & 4 & 2 & $4-6$ & $2-3$ & ---- & 4 & $\begin{array}{l}\text { semicircular com } \\
\text { pústulas na borda livre }\end{array}$ & 1 & $3-4$ \\
\hline P. santafecinus ${ }^{\mathrm{D}}$ & 4 & 1 & $4-5$ & ausentes & presentes & 4 & $\begin{array}{l}\text { semicircular com } \\
\text { pústulas na borda livre }\end{array}$ & 1 & 6 \\
\hline \multicolumn{10}{|l|}{ P. cuvieri } \\
\hline P. albonotatus ${ }^{\mathrm{A}}$ & 4 & 4 & 5 & $5-7$ & presentes & 2 & $\begin{array}{l}\text { triangular com } \\
\text { margem irregular }\end{array}$ & 1 & 4 \\
\hline P. albonotatus ${ }^{\mathrm{E}}$ & ---- & 3 & $3-4$ & ---- & presentes & 2 & $\begin{array}{l}\text { semicircular a } \\
\text { triangular }\end{array}$ & 1 & $4-6$ \\
\hline P. centralis $^{\mathrm{A}}$ & 4 & 3 & $6-8$ & 3 & ausentes & 6 & $\begin{array}{l}\text { semicircular com } \\
\text { margem irregular }\end{array}$ & 1 & $3-4$ \\
\hline P. cuvieri $^{\mathrm{A}}$ & 4 & 3 & 3 & 8 & ausentes & 2 & $\begin{array}{l}\text { semicircular, coberta } \\
\text { por pústulas }\end{array}$ & 1 & 2 \\
\hline \multicolumn{10}{|l|}{ P. henselii } \\
\hline P. fernandezae ${ }^{\mathrm{F}}$ & 2 & 1 & 6 & 12 & ---- & 2 & $\begin{array}{l}\text { semicircular com } \\
\text { a borda serrilhada }\end{array}$ & 1 & 4 \\
\hline P. riograndensis ${ }^{\mathrm{E}}$ & 4 & $1-2$ & 4 & ---- & ausentes & 4 & $\begin{array}{l}\text { triangular com } \\
\text { margem irregular }\end{array}$ & 1 & $3-4$ \\
\hline
\end{tabular}

A = este trabalho; B = Sandoval \& Alvarez (2001); C = Nomura et al. (2003); D = Perotti \& Cespedez (1999); E = Sandoval (2002); F = Alcade et al. (2006); AAB = arena do assoalho bucal, BB = bolsa bucal, ATB = arena do teto bucal, LC = laterais à crista. *A larva descrita foi referida como sendo de Physalaemus fuscomaculatus.

Tabela 2. Comparação da morfologia do assoalho bucal das larvas de Leptodactylus pertencentes aos grupos de Leptodactylus fuscus e Leptodactylus melanonotus.

Table 2. Comparison of internal morphology of the buccal floor among Leptodactylus species of the L. fuscus and L. melanonotus species groups.

\begin{tabular}{|c|c|c|c|c|}
\hline $\begin{array}{c}\text { Grupo de } \\
\text { espécies/espécie }\end{array}$ & $\begin{array}{c}\text { Papilas } \\
\text { infralabiais }\end{array}$ & $\begin{array}{l}\text { Papilas } \\
\text { linguais }\end{array}$ & $\begin{array}{c}\text { Papilas AAB } \\
\text { (por lado) }\end{array}$ & $\begin{array}{r}\text { Papilas BB } \\
\text { (por lado) }\end{array}$ \\
\hline \multicolumn{5}{|l|}{ L. fuscus } \\
\hline L. elenae ${ }^{\mathrm{A}}$ & dois pares (par medial fundido) & 4 & 5 & $1-2$ \\
\hline L. furnarius $^{\mathrm{B}}$ & dois pares (par medial fundido) & 4 & $9-10$ & 4 \\
\hline L. fuscus ${ }^{\mathrm{C}}$ & três dispostas em fileira transversal & 4 & $10-15$ & $1-2$ \\
\hline L. fuscus ${ }^{\mathrm{D}}$ & dois pares (par medial fundido) & 4 & $8-9$ & ---- \\
\hline L. fuscus ${ }^{\mathrm{B}}$ & dois pares (par medial fundido) & 4 & $8-9$ & $6-7$ \\
\hline L. gracilis $^{\mathrm{C}}$ & dois pares (par medial fundido) & 4 & $8-10$ & $1-2$ \\
\hline L. latinasus ${ }^{\mathrm{D}}$ & dois pares (par medial fundido) & 4 & $4-5$ & ---- \\
\hline L. mystacinus ${ }^{\mathrm{C}}$ & dois pares (par medial fundido) & 4 & $7-8$ & ---- \\
\hline L. mystacinus ${ }^{\mathrm{D}}$ & dois pares (par medial fundido) & 4 & $8-10$ & ---- \\
\hline L. notoaktites $^{\mathrm{E}}$ & dois pares & 3 & $6-7$ & ---- \\
\hline L. spixi ${ }^{\mathrm{F}}$ & $\begin{array}{l}\text { dois pares (par medial com papilas } \\
\text { muito próximas) }\end{array}$ & 4 & $7-8$ & ---- \\
\hline \multicolumn{5}{|l|}{ L. melanonotus } \\
\hline L. petersii ${ }^{\mathrm{B}}$ & 3 & ausentes & $11-12$ & $5-6$ \\
\hline L. podicipinus ${ }^{\mathrm{B}}$ & 3 & ausentes & $6-7$ & $3-4$ \\
\hline L. podicipinus $* \mathrm{C}$ & 3 (a central é bifurcada) & ausentes & $10-15$ & $0-3$ \\
\hline L. pustulatus ${ }^{\mathrm{G}}$ & um par & 1 & +19 & ---- \\
\hline
\end{tabular}

A = Prado \& D'Heursel (2006); B = este trabalho; C = Wassersug \& Heyer (1988); D = Sandoval (2004); E = De Sá et al. (2007b); F = Bilate et al. (2006);

$\mathrm{G}=$ De Sá et al. (2007a). AAB = arena do assoalho bucal, $\mathrm{BB}=$ bolsa bucal. *A larva descrita foi originalmente atribuída à Leptodactylus wagneri. 
Tabela 3. Comparação da morfologia do teto bucal das larvas de Leptodactylus pertencentes aos grupos de Leptodactylus fuscus e Leptodactylus melanonotus. Table 3. Comparison of internal morphology of the buccal roof among Leptodactylus species of the L. fuscus and L. melanonotus species groups.

\begin{tabular}{|c|c|c|c|c|}
\hline $\begin{array}{c}\text { Grupo de } \\
\text { espécies/espécie }\end{array}$ & $\begin{array}{c}\text { Papilas } \\
\text { pós-nasais }\end{array}$ & $\begin{array}{c}\text { Formato da } \\
\text { crista mediana }\end{array}$ & $\begin{array}{c}\text { Papilas LC } \\
\text { (por lado) }\end{array}$ & $\begin{array}{c}\text { Papilas ATB } \\
\text { (por lado) }\end{array}$ \\
\hline \multicolumn{5}{|l|}{ L. fuscus } \\
\hline L. elenae ${ }^{\mathrm{A}}$ & 2 & ampla, semicircular & $1-2$ & 4 \\
\hline L. furnarius $^{\mathrm{B}}$ & 2 & semicircular & 1 & 4 \\
\hline L. fuscus ${ }^{\mathrm{C}}$ & 4 & triangular com ápice serrilhado & 1 & $4-5$ \\
\hline L. fuscus ${ }^{\mathrm{D}}$ & 2 & semicircular com margem irregular & 1 & 4 \\
\hline L. fuscus ${ }^{\mathrm{B}}$ & 2 & semicircular & 1 & $3-4$ \\
\hline L. gracilis $^{\mathrm{C}}$ & 2 & triangular, coberta por pústulas & 1 & $4-5$ \\
\hline L. latinasus $\mathrm{D}^{\mathrm{D}}$ & 2 & base ampla com margem irregular & 1 & $4-5$ \\
\hline L. mystacinus ${ }^{\mathrm{C}}$ & 4 & ampla, triangular & 1 & 4 \\
\hline L. mystacinus ${ }^{\mathrm{D}}$ & 2 & semicircular com margem irregular & 1 & 4 \\
\hline L. notoaktites ${ }^{\mathrm{E}}$ & 2 & semicircular com margem irregular & 1 & 4 \\
\hline L. spixi ${ }^{\mathrm{F}}$ & 2 & semicircular & 1 & 4 \\
\hline \multicolumn{5}{|l|}{ L. melanonotus } \\
\hline L. petersii ${ }^{\mathrm{B}}$ & 2 & semicircular & 1 & $5-6$ \\
\hline L. podicipinus ${ }^{\mathrm{B}}$ & 2 & triangular & 1 & $7-8$ \\
\hline L. podicipinus $* \mathrm{C}$ & 2 & triangular & 1 & $6-8$ \\
\hline L. pustulatus ${ }^{\mathrm{G}}$ & 4 & triangular com margem irregular & 0 & 17 \\
\hline
\end{tabular}

A = Prado \& D'Heursel (2006); B = este trabalho; C = Wassersug \& Heyer (1988); D = Sandoval (2004); E = de Sá et al. (2007b); F = Bilate et al. (2006); $\mathrm{G}=$ De Sá et al. (2007a). ATB = arena do teto bucal, LC = laterais à crista. *A larva descrita foi originalmente atribuída à Leptodactylus wagneri.

à crista mediana e três a cinco papilas laterais à arena do teto bucal (Wassersug \& Heyer 1988, Sandoval 2004, Bilate et al. 2006, Prado \& D’Heursel 2006, de Sá et al. 2007b).

Informações acerca do grupo de Leptodactylus melanonotus são escassas, tanto para os indivíduos adultos quanto para larvas (Heyer 1970, Heyer 1994). Apesar disto, os dados neste estudo e no estudo de Wassersug \& Heyer (1988) e de Sá et al. (2007a). No assoalho bucal de $L$. petersii e $L$. podicipinus são similares a presença de três papilas infralabiais, papilas agrupando-se lateralmente nos limites anteriores do velum ventral, poucas papilas delimitando a arena do teto (cinco a oito), um par de papilas pós-nasais, um par de papilas laterais à crista mediana, glote descoberta e ausência de papila lingual. Houve variação entre a quantidade de papilas delimitando a arena do assoalho, maior nas larvas de $L$. petersii, e no formato da crista mediana, semicircular em L. petersii e triangular em L. podicipinus. Variação interpopulacional também foi encontrada entre a morfologia bucal da larva de $L$. podicipinus aqui descrita e aquela realizada por Wassersug \& Heyer (1998), com espécimes provenientes do município de Curuçá, estado do Pará, no Brasil. No assoalho bucal, os espécimes provenientes de Curuçá apresentam papila infralabial central bifurcada e poucas papilas anteriores às bolsas bucais. As características do teto bucal foram as mesmas para ambas as populações. A morfologia bucal das larvas de L. pustulatus descrita por de Sá et al. (2007a) difere por apresentar um maior número de papilas delimitando a arena do teto bucal (cerca de 17), dois pares de papilas pós-nasais, ausência das papilas laterais da crista, um par de papilas infralabiais e uma papila lingual.

Comparando-se a morfologia bucal interna larvária das espécies abordadas neste trabalho com as disponíveis para outras espécies de Physalaemus (Perotti \& Cespedez 1999, Sandoval \& Alvarez 2001, Alcade 2006) e de Leptodactylus pertencentes aos grupos de espécies de fuscus e melanonotus (Wassersug \& Heyer 1988, Sandoval 2004, Bilate et al. 2006, Prado \& D’Heursel 2006, de Sá et al. 2007a,b) percebe-se que as estruturas e formas do assoalho e teto bucal apre- sentam padrões muito conservativos e semelhantes entre espécies próximas. Isto sugere que estes dados possam ser informativos e que ao serem utilizados em conjunto com análises morfológicas do adulto e estudos moleculares, possam auxiliam na elucidação das relações filogenéticas das famílias Leiuperidae e Leptodactylidae e promover uma sistemática bem-suportada para a ordem Anura.

\section{Agradecimentos}

Os autores agradecem ao CNPq pela concessão da bolsa de iniciação científica à Núbia E. de O. Miranda (proc. 114466/2005-0), à UFMT e a FAPEMAT (proc. 0769/2006) pelo suporte financeiro ao projeto. À UNICAMP, especialmente à Profa. Dra. Heidi Dolder, pela concessão do uso do laboratório para análises em microscopia eletrônica de varredura. Os animais foram coletados com autorização do IBAMA/RAN (proc. 02013.004560/04-51).

\section{Referências Bibliográficas}

ALCADE, L., NATALE, G.S. \& CAJADE, R. 2006. The tadpole of Physalaemus fernandezae (Anura: Leptodactylidae). Herpetol. J. 16(2):203-211.

BILATE, M., WOGEL, H., WEBER, L.N. \& ABRUNHOSA, P.A. 2006. Vocalizações e girino de Leptodactylus spixi Heyer, 1983 (Amphibia, Anura, Leptodactylidae). Arq. Mus. Nac. Rio de Janeiro, 64(3):235-245

BOKERMANN, W.C.A. 1962. Observações biológicas sobre Physalaemus cuvieri Titz., 1826 (Amphibia, Salientia). Rev. Brasil. Biol. 22:391-399.

CARAMASCHI, U., FEIO, R.N. \& SÃO-PEDRO, V.A. 2008. A new species of Leptodactylus Fitzinger (Anura, Leptodactylidae) from Serra do Brigadeiro, State of Minas Gerais, Southeastern Brazil. Zootaxa, 1861:44-54.

CEI, J.M. 1980. Amphibians of Argentina. Monitore Zoologico Italiano (N. S.) Ita. J. Zool. 2:1-609. 
de Sá, R.O., Brandão, R. \& Dall'Ara Guimarães, L. 2007a. Description of the tadpole of Leptodactylus pustulatus Peters, 1870 (Anura: Leptodactylidae). Zootaxa, 1523:49-58.

De SÁ, R.O., LANGONE, J.A. \& SEGALLA, M.V. 2007b. The tadpole of Leptodactylus notoaktites Heyer, 1978 (Anura, Leptodactylidae). S. Am. J. Herpetol. 2(1):69-75.

D'Heursel, A. \& Haddad, C.F.B. 2007. Anatomy of the oral cavity of hylid larvae from the genera Aplastodiscus, Bokermannohyla, and Hypsiboas (Amphibia, Anura): description and systematic implications. J. Herpetol. 41(3):458-468.

D’Heursel, A. \& De SÁ, R.O. 1999. Comparing the tadpoles of Hyla geographica and Hyla semilineata. J. Herpetol. 33(3):353-361.

ETEROVICK, P.C. \& SAZIMA, I. 2000. Description of the tadpole of Leptodactylus syphax, with a comparison of morphological and ecological characters of tadpoles and adults of the species in the L. pentadactylus group (Leptodactylidae, Anura). Amphibia-Reptilia, 21:341-350.

FROST, D.R. 2008. Amphibia Species of the World: an Online Reference. American Museum of Natural History, New York. Disponível em: $<$ http://research.amnh.org/herpetology/amphibia〉. (último acesso em 11/08/2008).

FROST, D.R., GRANT, T., FAIVOVICH, J., BAIN, R.H., HAAS, A., HADDAD, C.F.B., De SÁ, R.O., CHANNING, A., WILKINSON, M., DONELLAN, S.C., RAXWORTHY, C.J., CAMPBELL, J.A., BLOTTO, B.L., MOLER, P., DREWES, R.C., NUSSBAUM, R.A., LYNCH, J.D., GREEN, D.M. \& WHEELER, W.C. 2006. The Amphibian Tree of Life. B. Am. Mus. Nat. Hist. 297:1-370.

GOSNER, K.L. 1960. A simplified table for staging anuran embryos and larvae with notes on identification. Herpetologica, 16:183-190.

GRANT, T., FROST, D.R., CALDWELL, J.P., GAGLIARDO, R., HADDAD, C.F.B., KOK, P.J.R., BRUCE MEANS, D., NOONAN, B.P., SCHARGEL, W.E. \& WHEELER, W.C. 2006. Phylogenetic systematic of dart-poison frogs and their relatives (Amphibia: Athesphatanura: Dendrobatidae). B. Am. Mus. Nat. Hist. 299:1-262.

HAAS, A. 2003. Phylogeny of frogs as inferred from primarily larval characters (Amphibia; Anura). Cladistics, 19:23-89.

HEYER, W.R. 1969. The adaptive ecology of the species group of the genus Leptodactylus (Amphibia, Leptodactylidae). Evolution, 23:421-428.

HEYER, W.R. 1970. Studies on the frogs of the genus Leptodactylus (Amphibia: Leptodactylidae). VI. Biosystematics of the melanonotus group. Contrib. Sci. Nat. Hist. Mus. Los Angeles Co. 191:1-48.

HEYER, W.R. 1994. Variation within the Leptodactylus podicipinus-wagneri complex of frogs (Amphibia: Leptodactylidae). Smithson. Contr. Zool. 546:1-124.

HEYER, W.R., RAND, A.S., CRUZ, C.A.G., PEIXOTO, O.L. \& NELSON, C.E. 1990. Frogs of Boracéia. Arq. Zool. Mus. Zool. Univ. São Paulo, 31(4):231-410.

KEHR, A. I., SCHAEFER, E.F. \& DURÉ, M.I. 2004. The tadpole of Physalaemus albonotatus (Anura: Leptodactylidae). J. Herpetol. 38(1):145-148.

LYNCH, J.D. 1970. Systematic status of the american leptodactylid frog genera Engystomops, Eupemphix e Physalaemus. Copeia, 1970(3):488-496.

NASCIMENTO, L.B., CARAMASCHI, U. \& CRUZ, C.A.G. 2005. Taxonomic review of the species groups of the genus Physalaemus Fitzinger, 1826 with revalidation of the genera Engystomops Jiménez-de-la-Espada, 1872 and Eupemphix Steindachner, 1863 (Amphibia, Anura, Leptodactylidae). Arq. Mus. Nac. Rio de Janeiro, 63(2):297-320.
NASCIMENTO, L.B., PIMENTA, B.V.S., CRUZ, C.A.G. \& CARAMASCHI, U. 2006. Taxonomic status of Gomphobates marmoratus Reinhardt and Lütken, 1862 "1861” ans Eupemphix fuscomaculatus Steindachner, 1864 (Amphibia, Anura, Leptodactylidae). S. Am. J. Herpetol. 1(3):166-174.

NOMURA, F., ROSSA-FERES, D.C. \& PRADO, V.H.M. 2003. The tadpole of Physalaemus fuscomaculatus (Anura: Leptodactylidae), with a description of internal oral morphology. Zootaxa, 370:1-8.

PEROTTI, M.G. 1997. The tadpole of Physalaemus cuqui Lobo, 1993 (Amphibia, Anura, Leptodactylidae). Amphibia-Reptilia, 18:427-432.

PEROTTI, M.G. \& CÉSPEDEZ, J.A. 1999. The tadpole of Physalaemus santafecinus, with comments on buccopharyngeal morphology. J. Herpetol. 33(2):312-315.

PRADO, C.P.A. \& D'Heursel, A. 2006. The tadpole of Leptodactylus elenae (Anura: Leptodactylidae), with the description of the internal buccal anatomy. S. Am. J. Herpetol. 1(1):79-86.

PUGENER, L.A., MAGLIA, A.M. \& TRUEB, L. 2003. Revisiting the contribution of larval characters to an analysis of phylogenetic relationships of basal anurans. Zool. J. Linn. Soc-Lond. 139:129-155.

ROSSA-FERES, D.C. \& JIM, J. 1993. Tadpole of Physalaemus centralis (Anura, Leptodactylidae). Copeia, 1993(2):566-569.

ROSSA-FERES, D.C. \& NOMURA, F. 2006. Characterization and taxonomic key for tadpoles (Amphibia: Anura) from the northwestern region of São Paulo State, Brazil. Biota Neotropica 6(1): http://www.biotaneotropica. org.br/v6n1/pt/abstract?identificationkey+bn00706012006 (último acesso em 17/08/2008)

SANDOVAL, M.T. 2002. Descripción del disco oral y cavidad bucofaríngea de larvas de dos espécies de anuros de la família Leptodactylidae. Reunión de comunicaciones científicas de La UNNE, Corrientes.

SANDOVAL, M.T. 2004. Microanatomía oral y bucal de las larvas de tres especies de Leptodactylus (Anura, Leptodactylidae). Rev. Esp. Herpetol. 18:79-87.

SANDOVAL, M.T. \& ALVAREZ, B.B. 2001. Microanatomía del disco oral y cavidad bucal de larvas de anuros. Reunión de comunicaciones científicas de la UNNE, Corrientes.

SOKOL, O.M. 1975. The phylogeny of anuran larvae: a new look. Copeia, 1975:1-23.

WASSERSUG, R.J. 1976. Oral morphology of anuran larvae: terminology and general description. Occas. Papers Mus. Nat. Hist. Univ. Kansas, 48:1-23.

WASSERSUG, R.J. \& DUELLMAN, W.E. 1984. Oral structures and their development in egg-brooding hylid frogs embryos and larvae: evolutionary and ecological implications. J. Morphol. 182:1-37.

WASSERSUG, R.J. \& HEYER, W.R. 1988. A survey of internal oral features of Leptodactyloid larvae (Amphibia: Anura). Smithson. Contr. Zool. 457:1-99.

WEBER, L.N. \& CARAMASCHI, U. 2006. Descrição da morfologia oral interna de larvas do gênero Crossodactylus Duméril \& Bibron, 1841 (Amphibia, Anura, Leptodactylidae). Arq. Mus. Nac. Rio de Janeiro, 64(2):141-149.

Recebido em 06/01/09 Versão reformulada recebida em 05/05/09 Publicado em 15/06/09 